\title{
Desain Bangunan Eks Kolonial Terkait Kenyamanan Visual dengan Pencahayaan Alami Studi Kasus Gedung Negara Cirebon
}

\author{
Nur Laela Latifah ${ }^{1}$, Ramadhan Paskal Dinda Wigna ${ }^{1}$, Teguh Darmawan ${ }^{1}$, \\ Saefulloh Karim Mundika ${ }^{1}$ \\ ${ }^{1}$ Program Studi Arsitektur, Fakultas Arsitektur dan Desain \\ Itenas, Institut Teknologi Nasional Bandung \\ Email: ela@itenas.ac.id
}

\begin{abstract}
ABSTRAK
Bangunan eks kolonial merupakan warisan bernilai sejarah tinggi yang harus dilestarikan, salah satunya Gedung Negara Cirebon. Fungsi bangunan ini sebagai tempat penginapan tetap dipertahankan, di samping terdapat ruang yang menjadi area kerja dan pada masa depan direncanakan menjadi fasilitas sumber budaya. Dalam melakukan aktivitas dan kerja visual dibutuhkan cahaya alami dengan kuantitas dan sesuai agar pengguna tetap dapat memperoleh kenyamanan visual, dan hal ini sangat ditentukan oleh desain bangunan terutama orientasi bangunan dan bukaan cahaya; alokasi dan kedalaman ruang; dimensi, bentuk, posisi, dan spesifikasi bukaan cahaya; serta reflektansi permukaan. Terkait Gedung Negara yang telah ditetapkan menjadi bangunan cagar budaya dimana kondisi fisiknya harus dipertahankan, penting untuk dikaji apakah dengan desain yang ada sebagai bangunan eks kolonial, dapat memberikan kuat penerangan yang mendukung perolehan kenyamanan visual bagi penggunanya. Metoda analisis dilakukan baik kuantitatif dan kualitatif, dan pada analisis kuantitatif dilakukan pengukuran di lokasi juga simulasi model menggunakan software Revit 2020 dan DIALux evo 8.2 yang hasilnya dibandingkan dengan standar kenyamanan visual terkait kuat penerangan. Diharapkan melalui penelitian ini diperoleh nilai manfaat agar dapat mengoptimalkan potensi cahaya alami bagi pengguna bangunan eks kolonial dengan tetap menjaga kelestariannya sebagai bangunan cagar budaya.
\end{abstract}

Kata kunci: desain bangunan eks kolonial, kenyamanan visual, pencahayaan alami.

\begin{abstract}
The ex-colonial building is a legacy of high historical value that must be preserved, one of which is the Gedung Negara Cirebon. The function of this building as a place to stay will still be maintained, in addition to having space which is a work area, and in the future it is planned to be a cultural resource facility. In carrying out visual activities and work natural light is needed in an appropriate quantity so that users can still get visual comfort, and this is very much determined by the building design, especially the orientation of the building and light openings; allocation and depth of space; dimensions, shape, position, and specifications of openings; as well as surface reflectance. Regarding the Gedung Negara Cirebon which has been designated as a cultural heritage building where its physical condition must be maintained, it is important to study whether the existing design as an ex-colonial building can provide illuminance that supports the acquisition of visual comfort for its users. The analysis method is carried out both quantitatively and qualitatively, and in the quantitative analysis measurements are carried out at the location as well as model simulations using the Revit 2020 and DIALux evo 8.2 software whose results are compared with visual comfort standards related to illuminance. It is hoped that through this research, beneficial values can be obtained in order to optimize the potential of natural light for users of ex-colonial buildings while maintaining their preservation as cultural heritage buildings.
\end{abstract}

Keywords: ex colonial building design, visual comfort, natural lighting. 


\section{PENDAHULUAN}

Indonesia adalah salah satu negara bekas jajahan Belanda yang mewariskan arsitektur khas bergaya kolonial yang dibangun pada masa pemerintahannya. Belanda menduduki beberapa kota strategis di Indonesia dan membangun gedung-gedung dengan fungsi penting seperti benteng, balai kota, kantor, bank, rumah dinas, dan gereja. Salah satu kota yang sangat kental oleh pengaruh kolonial adalah Cirebon, dimana terdapat bangunan-bangunan bernilai sejarah tinggi yang keberadaannya hingga kini tetap dilestarikan, seperti Balaikota Cirebon, Gedung Negara Cirebon, Bank Indonesia Cirebon, dan Gedung BAT.

Menurut Handinoto (2012) gaya arsitektur kolonial di Indonesia dibagi menjadi 3 periode, yaitu Indische Empire/ Imperial (berlangsung abad 18-19) yang dipelopori Herman Willen Deandels dengan ciri khas utama terdapat akulturasi budaya Belanda, Indonesia, dan sedikit Cina; lalu Arsitektur Transisi (1890-1915) dengan ditandai adanya teknologi dan kebijakan politik yang baru; dan terakhir Arsitektur Kolonial Modern (1915-1940) yang dipengaruhi arsitek Belanda dari akademisi [1]. Semua bangunan pada 3 periode ini memiliki nilai sejarah tinggi, dan periode Indische Empire memiliki keistimewaan karena merupakan masa cikal bakal wujud bangunan kolonial di Indonesia. Gedung Negara Cirebon didirikan pada tahun 1865 pada masa pemerintahan Karesidenan Cirebon Albert Wilhelm Kinder De Camurecq. Bangunan yang dirancang oleh arsitek Belanda Van De Berg ini memiliki ciri-ciri khas periode Indische Imperial, dimana terdapat akulturasi budaya Belanda dan Indonesia. Handinoto (2012) menyatakan ciri-ciri bangunan kolonial periode Indische Imperial antara lain denah lantai simetris penuh dimana terdapat ruang tengah yang terhubung dengan teras depan dan belakang, terdapat kolom Yunani pada teras, serta area servis seperti dapur, kamar mandi, dan gudang yang terpisah dengan bangunan utama [1]. Wardiningsih (2015) menyatakan bahwa Arsitektur Nusantara identik dengan Arsitektur Indonesia dengan konsep komponen bangunan kepala, badan, dan kaki, lalu ada beberapa hal yang mempengaruhi wujud arsitektur yaitu agama, budaya dan adat/ tradisi, filosofi, serta iklim [2].

\section{METODOLOGI}

\subsection{Kasus Studi}

Gedung Negara sebagai bangunan eks kolonial periode Indische Imperial yang awalnya difungsikan sebagai rumah dinas residen, memiliki akulturasi budaya Belanda dan Indonesia dengan wujud denah lantai cenderung simetris dan terdapat beberapa ruang di tengah bangunan yang tidak langsung memperoleh cahaya matahari, memiliki kepala berupa atap perisai lebar yang identik dengan arsitektur Indonesia beriklim tropis, serta memiliki kaki berupa teras depan dan belakang yang diangkat hampir $1,00 \mathrm{~m}$ dari permukaan tanah. Bangunan hanya terdiri atas 1 lantai dan luasnya cukup besar hingga $2.120 \mathrm{~m}^{2}$. Sebagai bangunan utama dengan toilet hanya ada di kamar tidur 1, 2, dan 4, maka seluruh area ruang lain dapat digunakan beraktivitas hingga bagian terdalam yang terjauh dari bukaan cahaya. Teras depan dan belakang dinaungi atap lebar dengan tumpuan kolom-kolom Yunani, yang semuanya ini dapat membayangi bukaan cahaya.

Pada tahun 2001 Gedung Negara ditetapkan menjadi salah satu Bangunan Cagar Budaya (BCB) Golongan B (madya) karena memenuhi 3 (tiga) kriteria, yaitu nilai arsitektural, nilai sejarah, dan umur bangunan [3]. Cagar budaya adalah warisan budaya bersifat kebendaan yang berupa benda cagar budaya, bangunan cagar budaya, struktur cagar budaya, situs cagar budaya, dan kawasan cagar budaya di darat dan/ atau di air yang perlu dilestarikan keberadaannya karena memiliki nilai penting bagi sejarah, ilmu pengetahuan, pendidikan, agama, dan/ atau kebudayaan melalui proses penetapan [3]. Dengan statusnya ini bila melakukan renovasi maka harus mengikuti aturan yang telah ditetapkan berdasarkan UU No. 11 Tahun 2010 tentang Cagar Budaya Pasal 77 Ayat (1) mengenai pemugaran bangunan cagar budaya [4]. Hingga kini Gedung Negara masih difungsikan sebagai tempat penginapan (rumah dinas bagi tamu Gubernur Jawa Barat), dan terdapat ruang yang difungsikan sebagai area kerja. 
Pada waktu tertentu sering menjadi tempat pagelaran seni budaya tingkat nasional, dan direncanakan pada masa berikutnya fungsi ini tetap berjalan.
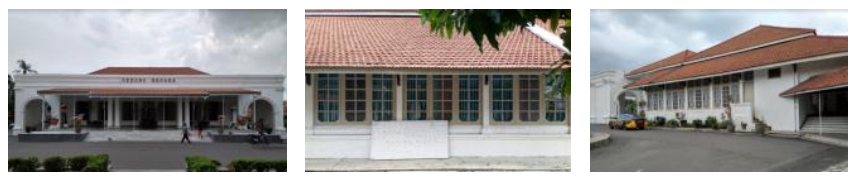

Gambar 1. Gedung Negara dari Arah Depan, Samping Kanan, dan Kiri Belakang Sumber: R.P.D. Wigna, dkk. (2020) [5]

Walaupun fasad Gedung Negara memiliki bukaan cahaya berukuran cukup besar, perlu untuk dikaji dengan desain sebagai bangunan kolonial seperti ini, bila hanya dengan mengandalkan pencahayaan alami pada ruang dalam apakah pengguna masih dapat memperoleh kenyamanan visual dimana ruang harus cukup terang dengan kuat penerangan terukur memenuhi standar. Sebagai bangunan cagar budaya, terkait optimalisasi kenyamanan visual hal ini menjadi perhatian penting dimana kolom, dinding, atap lebar, dan bukaan cahaya harus tetap dipertahankan bentuknya seperti kondisi asli, walaupun ternyata setelah dikaji terdapat area pada ruang yang dengan kedalaman dimensinya atau karena lokasinya di tengah bangunan belum dapat memenuhi syarat kenyamanan visual (kurang terang). Untuk itu dalam penelitian ini akan terdapat usulan sebagai solusi untuk membantu meningkatkan kenyamanan visual pengguna pada Gedung Negara dengan tetap mempertahankan kelestarian bangunannya.

\subsection{Lingkup Kajian}

Lingkup kajian terkait kenyamanan visual dengan pencahayaan alami meliputi orientasi bangunan dan bukaan cahaya; alokasi ruang; dimensi, bentuk, dan posisi bukaan cahaya; kedalaman ruang; spesifikasi bukaan cahaya; kuat penerangan; serta reflektansi permukaan.

\subsection{Metoda Pengukuran dan Analisis}

Analisis dilakukan baik secara kuantitatif dan kualitatif sesuai dengan lingkup kajian yang ditinjau. Pada analisis kuantitatif dilakukan pengukuran lapangan menggunakan alat Luxmeter juga simulasi model menggunakan software Revit 2020 dan DIALux evo 8.2 untuk memperoleh gambaran kuat penerangan yang terjadi, yang hasilnya dibandingkan dengan standar. Titik pengukuran di lokasi dan pada model simulasi telah ditentukan yaitu Titik Ukur Utama (TUU) dan Titik Ukur Samping (TUS 1 dan TUS 2). Semua titik ini diambil sejauh $1 / 3$ d dari bidang lubang cahaya efektif pada suatu bidang kerja yaitu bidang datar setinggi 0,75 meter di atas lantai [6], dimana d adalah jarak antar permukaan dalam bidang dinding berhadapan dengan salah satunya terdapat lubang cahaya efektif tersebut. Waktu pengukuran di lokasi antara 08.00-16.00, sedangkan waktu simulasi pada 3 tanggal sesuai lintasan matahari di langit yaitu 22 Juni 2020 (terjauh di Utara), 22 September 2020 (melintasi lokasi), dan 22 Desember 2020 (terjauh di Selatan).

\subsection{Tujuan dan Nilai Manfaat Penelitian}

Tujuan penelitian adalah memberi wawasan bagaimana desain bangunan eks kolonial berpengaruh terdapat perolehan kenyamanan visual, pada ruang dalam sesuai fungsinya. Diharapkan melalui penelitian ini diperoleh nilai manfaat agar dapat mengoptimalkan potensi cahaya alami bagi pengguna bangunan eks kolonial dengan tetap mempertahankan kondisi fisiknya yang merupakan cagar budaya.

\section{TEORI}

\subsection{Pencahayaan Alami}

Pencahayaan alami adalah penggunaan cahaya yang bersumber dari alam dengan sumber utama dari matahari [7]. Desain dengan pemanfaatan cahaya alami akan lebih baik bila mempertimbangkan terjadinya filter cahaya oleh langit dan awan serta pemantulan oleh material permukaan baik alami maupun buatan. Jumlah relatif cahaya yang diterima bangunan ditentukan posisi matahari, kondisi 
langit, serta bentuk dan sifat reflektansi material permukaan termasuk objek-objek di sekeliling bangunan [8].

\subsection{Orientasi Bangunan dan Bukaan Cahaya}

Arah datang cahaya matahari yang konstan dari Timur ke Barat maka setiap sisi bangunan akan memperoleh kualitas dan kuantitas cahaya alami yang berbeda [9]. Livingston (2014) dalam buku yang disusun Manurung (2017) menyatakan bahwa terkait penerimaan cahaya matahari oleh bangunan, sisi Utara menerima paling konsisten, sisi Selatan menerima dengan variasi beragam, sedangkan sisi Timur dan Barat menerima secara langsung [10]. Cahaya dari sisi Utara bersifat tak langsung dengan disertai panas yang kecil sehingga memungkinkan dimasukkan dengan kuantitas besar melalui bukaan cahaya yang besar, sementara cahaya dari sisi Timur dan Barat bersifat langsung dengan disertai panas [9]. Bila memungkinkan orientasikan bangunan ke arah Utara Selatan agar efektif diperoleh cahaya tak langsung [8].

\subsection{Alokasi Ruang}

Philips (2004) dalam buku yang disusun Manurung (2017) menyatakan bahwa kamar tidur dan dapur sangat baik bila dialokasikan di sisi Timur untuk memperoleh cahaya matahari pagi, sedangkan ruang lain yang lebih banyak digunakan sore dan malam hari sebaiknya dialokasikan di sisi Selatan atau Timur bangunan [11].

\subsection{Dimensi, Bentuk, dan Posisi Bukaan Cahaya}

Berdasarkan rasio antara dimensi tinggi dan lebarnya, bentuk bukaan cahaya pada bidang dinding dapat dikategorikan menjadi bukaan horizontal (rasio $1: 2$ ), bukaan vertikal (rasio $2: 1$ ), dan bukaan menengah (rasio antara 0,5 hingga 2). Bentuk bukaan cahaya ini memengaruhi distribusi cahaya pada ruang. Berdasarkan skala manusia, dimensi bukaan cahaya pada bidang dinding dapat dikategorikan menjadi bukaan kecil (luas kurang dari $0,5 \mathrm{~m}^{2}$ ), bukaan sedang (luas antara 0,5 $\mathrm{m}^{2}-2 \mathrm{~m}^{2}$ ), dan bukaan besar (luas lebih dari $2,0 \mathrm{~m}^{2}$ ), dimana bukaan kecil dapat memberi efek silau [12]. Untuk mendapatkan cahaya alami yang baik pada bangunan dapat mengoptimalkan luas bukaan atau WWR (Window to Wall Ratio) [13]. Untuk mendukung perolehan kenyamanan visual, luas bukaan cahaya pada fasad bangunan adalah minimal 20\% luas dinding (Window to Wall Ratio/ WWR lebih besar dari 1:5) [7].

Posisi bukaan cahaya ditinjau dari tinggi dinding dapat dikategorikan menjadi bukaan tinggi, menengah, dan rendah, dimana makin tinggi posisinya maka makin baik untuk memasukkan dan mendistribusikan cahaya ke dalam ruang. Posisi bukaan cahaya ditinjau dari lebar dinding dapat dikategorikan menjadi bukaan tengah, samping, dan sudut, dimana posisi di tengah memberikan distribusi cahaya lebih baik ke dalam ruang [12].

\subsection{Kedalaman Ruang}

Semakin besar kedalaman ruangan, maka semakin berkurang cahaya masuk ke dalam ruang, karena mengalami refleksi dan absorpsi oleh material yang dilaluinya. Sebagai ketentuan kedalaman ruang (D) tidak lebih dari 1,5 hingga 2,5 kali tinggi ambang atas bukaan cahaya $(\mathrm{H})$, untuk itu elevasi plafon dinaikkan bila memungkinkan [14].

\subsection{Spesifikasi Bukaan Cahaya}

Dengan warna yang sama, makin tebal kaca maka makin rendah kemampuan transmisi cahayanya sedangkan kemampuan serap cahayanya makin besar [7]. Kaca polos terang tebal 1-4 mm memiliki kemampuan transmisi cahaya 90\%-92\% sedangkan kaca es tebal 2-3 mm hanya 63\%-78\% [15]. Indofloat Clear Glass $5 \mathrm{~mm}$ memiliki kemampuan transmisi cahaya 89\% [16].

\subsection{Kuat Penerangan}

Cahaya memiliki peran penting bagi pengguna bangunan dalam melakukan aktivitas dan kerja visual. Dengan adanya cahaya, maka informasi visual terkait bangunan atau karya arsitektur lainnya, baik bentuk, dimensi, warna, detail, serta teksturnya dapat diterima oleh pengguna [9], sehingga sangat mendukung dalam mengapresiasi bangunan terutama bangunan bersejarah atau cagar budaya yang 
umumnya sarat dengan detail ornamen baik pada pengolahan fasad maupun interiornya. Agar pengguna dapat mengakses objek visual dengan baik, maka diperlukan cahaya dengan kuantitas yang sesuai [9]. Makin berat kerja visual, maka makin tinggi kebutuhan minimal kuat penerangan yang harus terukur di titik ukur pada bidang kerja [7]. Ada 2 jenis titik ukur yaitu Titik Ukur Utama (TUU) dan Titik Ukur Samping (TUS). Faktor Langit (fl) di titik ukur tersebut harus memenuhi suatu nilai minimum tertentu yang ditetapkan menurut fungsi dan ukuran ruangannya [6], dengan mengacu pada Tabel 1 dan Tabel 2 berikut.

Tabel 1. Nilai Faktor Langit Bangunan Tempat Tinggal

\begin{tabular}{lcc}
\hline Jenis ruangan & $\mathrm{fl}_{\min }$ TUU & $\mathrm{fl}_{\min }$ TUS \\
\hline Ruang tinggal & $0,35 . \mathrm{d}$ & $0,16 . \mathrm{d}$ \\
\hline Ruang kerja & $0,35 . \mathrm{d}$ & $0,16 . \mathrm{d}$ \\
\hline Kamar tidur & $0,18 . \mathrm{d}$ & $0,05 . \mathrm{d}$ \\
\hline Dapur & $0,20 . \mathrm{d}$ & $0,20 . \mathrm{d}$ \\
\hline Sumber : SNI 03-2396-2001 [6] &
\end{tabular}

Tabel 2. Nilai Faktor Langit untuk Bangunan Umum

\begin{tabular}{ccc}
\hline Klasifikasi Pencahayaan & $\mathrm{fl}_{\min }$ TUU & $\mathrm{fl}_{\min }$ TUU \\
\hline A (kerja halus sekali) & $0,45 . \mathrm{d}$ & $40 \% \mathrm{fl}_{\min }$ TUU \\
\hline $\mathrm{B}$ (kerja halus) & $0,35 . \mathrm{d}$ & $40 \% \mathrm{fl}_{\min }$ TUU \\
\hline $\mathrm{C}$ (kerja sedang) & $0,25 . \mathrm{d}$ & $40 \% \mathrm{fl}_{\min }$ TUU \\
\hline D (kerja kasar) & $0,15 . \mathrm{d}$ & $40 \% \mathrm{fl}_{\min }$ TUU \\
\hline Sumber : SNI 03-2396-2001 [6], diolah &
\end{tabular}

\subsection{Reflektansi Permukaan}

Benda memiliki kemampuan pantul cahaya yang ditentukan oleh warna dan tekstur permukaannya, dimana makin cerah warnanya dan makin licin teksturnya maka makin tinggi kemampuan pantulnya [7] (lihat Tabel 3). Cahaya matahari dapat dimasukkan ke dalam ruangan dengan cara dibelokkan menggunakan reflektor [12].

Tabel 3. Daya Pantul Warna

\begin{tabular}{lc}
\hline Warna & Daya pantul (\%) \\
\hline Putih & $80-90$ \\
\hline Kuning muda, ros & 80 \\
\hline Beige muda, lilac & 70 \\
\hline Kuning mustard & 35 \\
\hline Coklat sedang, abu-abu & 25 \\
\hline Hitam & 10 \\
\hline \multicolumn{2}{c}{ Sumber : Brown (1990) [17] }
\end{tabular}

\section{DATA DAN ANALISIS}

\subsection{Layout Ruang}

Layout ruang Gedung Negara terbagi atas 3 zona yaitu sayap kiri, area tengah yang terhubung dengan teras, dan sayap kanan, dengan hanya kamar tidur 1, 2, dan 4 yang dilengkapi toilet. Desain layout seperti ini kurang baik karena terdapat ruang di tengah bangunan yaitu kamar tidur 3, 5, dan 6 serta ruang santai yang tidak terakses cahaya alami secara langsung, dan hal ini memungkinkan kuat penerangan yang terukur masih di bawah standar sesuai kerja visual pengguna. 


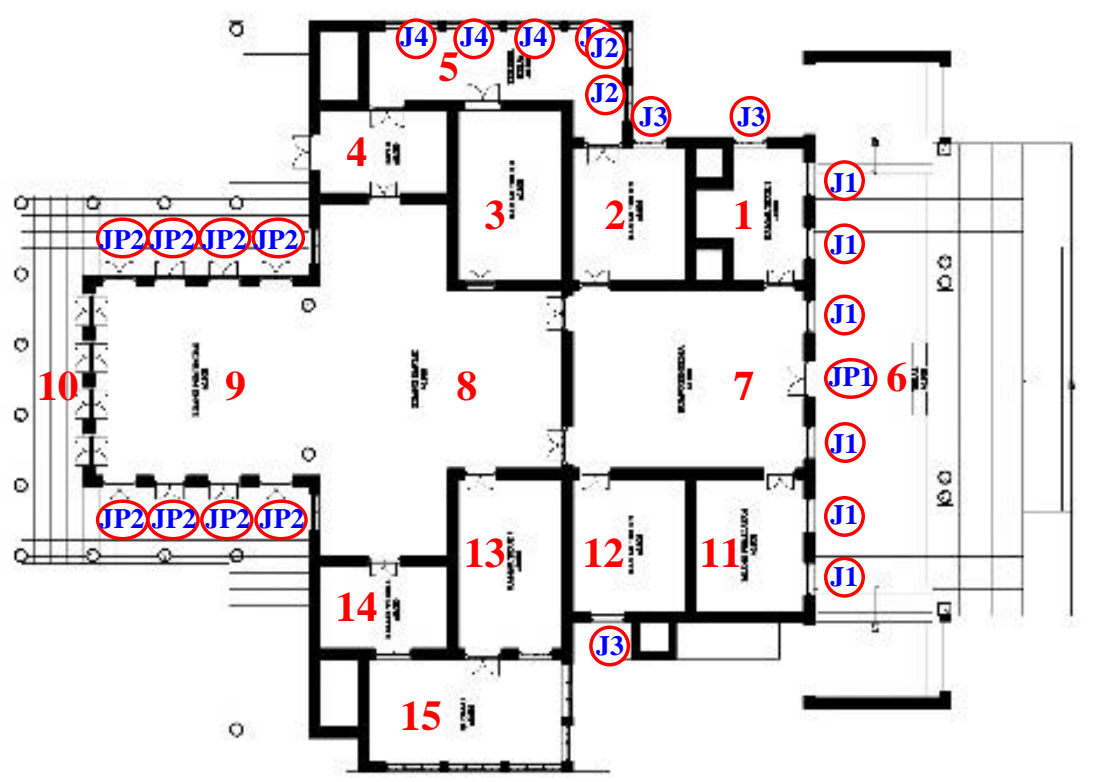

Keterangan sayap kiri:

1. Kamar tidur 1

2. Kamar tidur 2

3. Kamar tidur 3

4. Dapur

5. Koridor kerja

Keterangan area tengah:

6. Teras depan (outdoor)

7. Ruang penerima

8. Ruang santai

9. Ruang pertemuan

10. Teras belakang (outdoor)

Keterangan sayap kanan:

11. Ruang peralatan

12. Kamar tidur 4

13. Kamar tidur 5

14. Kamar tidur 6

15. Gudang

Gambar 2. Layout Ruang dan Tipe Bukaan pada Fasad Gedung Negara

Sumber: R.P.D. Wigna, dkk. (2020) [5], diolah

\subsection{Orientasi Bangunan dan Bukaaan Cahaya}

Orientasi fasad depan bangunan menghadap ke Timur dimana terdapat jalan raya. Bangunan memanjang Timur-Barat dengan bagian fasad terpanjang di sisi Utara dan Selatan. Seluruh sisi fasad memiliki bukaan cahaya. Dengan orientasi bangunan menghadap ke Timur dan gubahan massa yang memanjang Timur-Barat, maka dominansi bukaan cahaya otomatis terdapat pada sisi Utara dan Selatan yang efektif memperoleh cahaya tak langsung dengan lebih sedikit radiasi panas matahari. Desain orientasi bangunan dan bukaan ini sangat baik karena dapat mengopimalkan dimensi bukaan cahaya yang mendukung perolehan kuat penerangan untuk kenyamanan visual pengguna, terutama pada kamar tidur 1, 2, dan 4, koridor kerja, serta gudang.

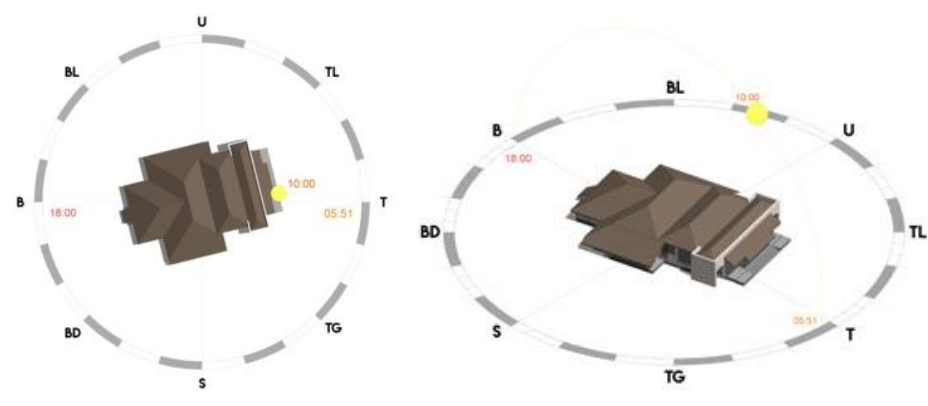

Gambar 3. Orientasi Bangunan dan Bukaan Gedung Negara Sumber: R.P.D. Wigna, dkk. (2020) [5]

\subsection{Alokasi Ruang}

Sesuai dengan posisi bukaan cahaya, sisi Timur bangunan dialokasikan untuk kamar tidur 1, ruang penerima, dan ruang peralatan (lihat Gambar 2). Sisi barat untuk alokasi dapur dan ruang pertemuan. Sisi Utara untuk kamar tidur 2 dan koridor kerja yang awalnya terbuka tetapi kemudian sisi terbukanya ditutup dinding. Sisi Selatan untuk kamar tidur 4 dan gudang. Dengan alokasi ruang seperti ini, tidak semua kamar tidur terdapat di sisi Timur untuk memperoleh cahaya matahari pagi, walaupun begitu alokasi kamar tidur 1, 2, dan 4 serta koridor kerja dapat dikatakan baik karena bukaan cahayanya menghadap Utara/ Selatan yang lebih sedikit terpapar radiasi panas matahari. Ditutupnya koridor berdampak kurang baik bagi kamar tidur 3 karena menjadi terhalang tidak memperoleh cahaya alami secara langsung. Area servis dapur masih baik dialokasikan di sisi Barat karena dilindungi atap teras 
belakang, tetapi alokasi gudang kurang baik berada di sisi Selatan karena area tersebut sebaiknya untuk kamar tidur 5 dan 6 yang tidak dapat memperoleh cahaya alami secara langsung.

\subsection{Dimensi, Bentuk, dan Posisi Bukaan Cahaya}

Berdasarkan dimensi dan bentuknya, terdapat 6 tipe bukaan jendela dan jendela-pintu yaitu J1, J2, J3, J4, JP1, dan JP2, yang masing-masing memiliki bagian transparan (kaca) dan masif (kusen/ daun pintu) (lihat Gambar 4). Bagian masif ini disertakan dalam perhitungan rasio dimensi terkait bentuk bukaan, tetapi tidak dalam perhitungan luas bukaan. Dengan tidak terdapat bukaan berdimensi kecil (luas kurang dari $0,5 \mathrm{~m}^{2}$ ) yang memberi efek silau bagi pengguna dalam ruang, kondisi ini sangat baik. Bukaan tipe $\mathrm{J} 1, \mathrm{~J} 2$, J3, dan J4 seluruhnya berbentuk antara horizontal dan vertikal (rasio bervariasi dari 1,10 hingga 1,88), dapat dikatakan baik dalam mendistribusikan cahaya hingga ke bagian dalam ruang. Bukaan tipe JP1 dan JP2 berbentuk vertikal dengan rasio lebih dari 2,0 maka sangat baik dalam mendistribusikan cahaya untuk menjangkau bagian ruang yang lebih dalam.

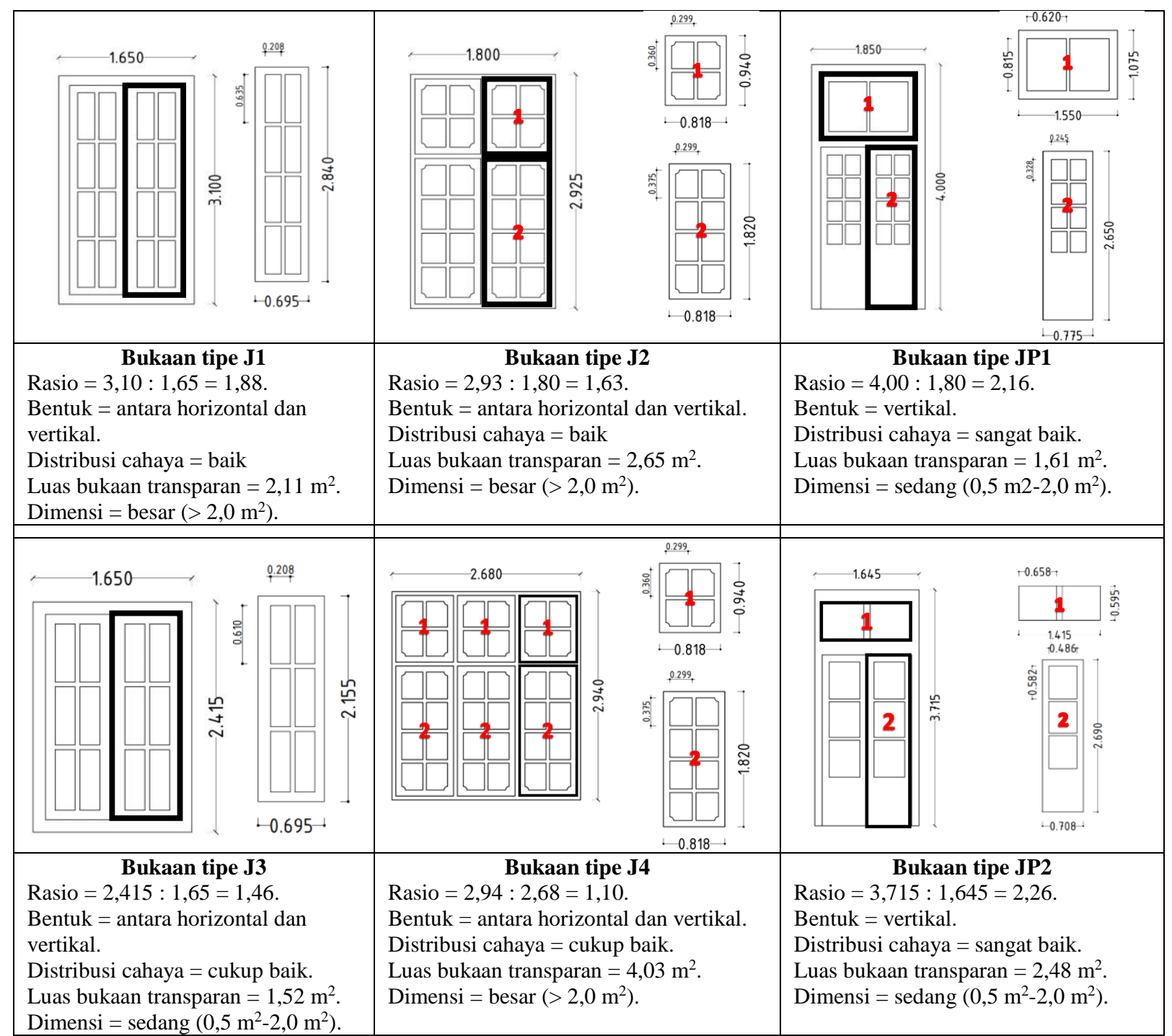

Gambar 4. Tipe Bukaan Berdasarkan Dimensi dan Bentuk pada Fasad Gedung Negara Sumber: R.P.D. Wigna, dkk. (2020) [5], diolah

Rasio bukaan (WWR) dihitung pada Tabel 4. Luas bukaan hanya dihitung pada bagian yang transparan (kaca). Luas fasad dihitung berdasarkan dimensi ruang dalam dengan tinggi diukur dari lantai sampai plafon. Koridor kerja merupakan area koridor terbuka yang kemudian ditutup dinding dan plafonnya miring (lihat Gambar 5) maka tinggi fasad dihitung rata-ratanya yaitu 5,50 +3,68)/2=4,59 $\mathrm{m}$. Fasad 
Barat ruang pertemuan ditutup tirai, bukaan pada sisi tersebut tidak difungsikan untuk memasukkan cahaya ke dalam ruang. Berdasarkan perhitungan WWR pada ruang di perimeter bangunan, secara keseluruhan kondisi WWR dapat dikatakan kurang baik karena hanya koridor kerja yang memiliki WWR lebih dari 20\% (22,42\% oleh J2 pada fasad Timur dan 28,30\% oleh J4 pada fasad Utara). WWR yang kurang dari $20 \%$ pada fasad lainnya berdampak kurang baik dalam usaha untuk mengkondisikan kuat penerangan yang terjadi dalam ruang dapat memenuhi standar kenyamanan visual.

Tabel 4. Rasio Bukaan pada Fasad Gedung Negara

\begin{tabular}{|c|c|c|c|c|c|}
\hline Orientasi & Fungsi ruang & Tipe bukaan & Luas bukaan & Luas fasad & WWR \\
\hline \multirow[t]{4}{*}{ Utara } & Kamar tidur 1 & $1 \times \mathrm{J} 3$ & $1,52 \mathrm{~m}^{2}$ & $5,27 \times 5,50=28,99 \mathrm{~m}^{2}$ & $5,24 \%<20 \%$ \\
\hline & Kamar tidur 2 & $1 \times \mathrm{J} 3$ & $1,52 \mathrm{~m}^{2}$ & $5,52 \times 5,50=30,36 \mathrm{~m}^{2}$ & $5,00 \%<20 \%$ \\
\hline & Koridor kerja & $4 \times \mathrm{J} 4$ & $4 \times 4,03=16,12 \mathrm{~m}^{2}$ & $12,41 \times 4,59=56,96 \mathrm{~m}^{2}$ & $28,30 \%>20 \%$ \\
\hline & Ruang pertemuan & $4 \times \mathrm{JP} 2$ & $4 \times 2,48=9,92 \mathrm{~m}^{2}$ & $10,50 \times 5,50=57,75 \mathrm{~m}^{2}$ & $17,18 \%<20 \%$ \\
\hline \multirow[t]{5}{*}{ Timur } & Koridor kerja & $2 \times \mathrm{J} 2$ & $2 \times 2,65=5,30 \mathrm{~m}^{2}$ & $5,15 \times 4,59=23,64 \mathrm{~m}^{2}$ & $22,42 \%>20 \%$ \\
\hline & Kamar tidur 1 & $2 \times \mathrm{J} 1$ & $2 \times 2,11=4,22 \mathrm{~m}^{2}$ & $6,50 \times 5,50=35,75 \mathrm{~m}^{2}$ & $11,80 \%<20 \%$ \\
\hline & Ruang penerima & $2 \times \mathrm{J} 1+1 \times \mathrm{JP} 1$ & $2 \times 2,11+1,61=5,83 \mathrm{~m}^{2}$ & $8,70 \times 5,50=47,85 \mathrm{~m}^{2}$ & $12,18 \%<20 \%$ \\
\hline & Ruang peralatan & $2 \times \mathrm{J} 1$ & $2 \times 2,11=4,22 \mathrm{~m}^{2}$ & $6,50 \times 5,50=35,75 \mathrm{~m}^{2}$ & $11,80 \%<20 \%$ \\
\hline & Gudang & (tidak dikaji) & - & - & - \\
\hline \multirow[t]{3}{*}{ Selatan } & Kamar tidur 4 & $1 \times \mathrm{J} 3$ & $1,52 \mathrm{~m}^{2}$ & $5,52 \times 5,50=30,36 \mathrm{~m}^{2}$ & $5,00 \%<20 \%$ \\
\hline & Gudang & (tidak dikaji) & - & - & - \\
\hline & Ruang pertemuan & $4 \times \mathrm{JP} 2$ & $4 \times 2,48=9,92 \mathrm{~m}^{2}$ & $10,50 \times 5,50=57,75 \mathrm{~m}^{2}$ & $17,18 \%<20 \%$ \\
\hline \multirow[t]{2}{*}{ Barat } & Dapur & (tidak dikaji) & - & - & - \\
\hline & Ruang pertemuan & (ditutup tirai) & - & - & - \\
\hline
\end{tabular}

Sumber: R.P.D. Wigna, dkk. (2020) [5], diolah

Terkait posisi bukaan ditinjau dalam arah tinggi dinding, semua tipe bukaan pada fasad memiliki kategori menengah, maka kondisi ini baik dalam memasukkan dan mendistribusikan cahaya ke dalam ruang. Terkait posisi bukaan ditinjau dalam arah lebar dinding, semua tipe bukaan pada fasad kecuali di kamar tidur 2 dan 4 berada di tengah, maka kondisi ini sangat baik untuk mendistribusikan cahaya ke dalam ruang. Posisi bukaan pada kamar tidur 2 dan 4 berada di samping, kondisi ini kurang baik karena distribusi cahaya ke dalam ruang menjadi kurang merata.

Tabel 5. Posisi Bukaan pada Fasad Gedung Negara

\begin{tabular}{|c|c|c|c|c|c|c|}
\hline Fungsi ruang & Tipe bukaan & $\begin{array}{l}\text { Tinggi ambang } \\
\text { atas bukaan }\end{array}$ & $\begin{array}{l}\text { Tinggi } \\
\text { fasad }\end{array}$ & $\begin{array}{l}\text { Persentase } \\
\text { posisi tinggi }\end{array}$ & $\begin{array}{l}\text { Posisi bukaan } \\
\text { arah tinggi }\end{array}$ & $\begin{array}{l}\text { Posisi bukaan } \\
\text { arah lebar }\end{array}$ \\
\hline \multirow[t]{2}{*}{ Kamar tidur 1} & $\mathrm{~J} 1$ & $4,00 \mathrm{~m}$ & $5,50 \mathrm{~m}$ & $4,00 / 5,50=72,73 \%$ & Menengah & Tengah \\
\hline & $\mathrm{J} 3$ & $3,24 \mathrm{~m}$ & $5,50 \mathrm{~m}$ & $3,24 / 5,50=58,91 \%$ & Menengah & Tengah \\
\hline Kamar tidur 2 & $\mathrm{~J} 3$ & $3,24 \mathrm{~m}$ & $5,50 \mathrm{~m}$ & $3,24 / 5,50=58,91 \%$ & Menengah & Samping \\
\hline \multirow[t]{2}{*}{ Koridor kerja } & $\mathrm{J} 2$ & $3,50 \mathrm{~m}$ & $4,59 \mathrm{~m}$ & $3,50 / 4,59=76,25 \%$ & Menengah & Tengah \\
\hline & $\mathrm{J} 4$ & $3,52 \mathrm{~m}$ & $4.59 \mathrm{~m}$ & $3,52 / 4,59=76,69 \%$ & Menengah & Tengah \\
\hline Dapur & (tidak dikaji) & - & - & - & - & - \\
\hline \multirow[t]{2}{*}{ Ruang penerima } & $\mathrm{J} 1$ & $4,00 \mathrm{~m}$ & $5,50 \mathrm{~m}$ & $4,00 / 5,50=72,73 \%$ & Menengah & \multirow{2}{*}{ Tengah } \\
\hline & JP1 & $4,00 \mathrm{~m}$ & $5,50 \mathrm{~m}$ & $4,00 / 5,50=72,73 \%$ & Menengah & \\
\hline Ruang pertemuan & JP2 & $3,72 \mathrm{~m}$ & $5,50 \mathrm{~m}$ & $3,72 / 5,50=67,64 \%$ & Menengah & Tengah \\
\hline Ruang peralatan & $\mathrm{J} 1$ & $4,00 \mathrm{~m}$ & $5,50 \mathrm{~m}$ & $4,00 / 5,50=72,73 \%$ & Menengah & Tengah \\
\hline Kamar tidur 4 & $\mathrm{~J} 3$ & $3,24 \mathrm{~m}$ & $5,50 \mathrm{~m}$ & $3,24 / 5,50=58,91 \%$ & Menengah & Samping \\
\hline Gudang & (tidak dikaji) & - & - & - & - & - \\
\hline
\end{tabular}

Sumber: R.P.D. Wigna, dkk. (2020) [5], diolah

\subsection{Kedalaman Ruang}

Kedalaman ruang (D) dihitung dari permukaan dinding dalam dimana terdapat bukaan cahaya yang ambang atasnya ditinjau, hingga ke permukaan dinding dalam di seberangnya. Tinggi ambang atas bukaan cahaya $(\mathrm{H})$ dihitung dari permukaan lantai ruang dalam. Bukaan tipe JP2 pada ruang pertemuan saling berhadapan, maka kedalaman ruang adalah jarak antara bukaan yang berseberangan dibagi 2, yaitu $0,5 \times 9,30 \mathrm{~m}=4,65 \mathrm{~m}$. Berdasarkan rasio $\mathrm{D}$ terhadap $\mathrm{H}$, kamar tidur 1 , koridor kerja, ruang pertemuan, dan ruang peralatan memiliki kedalaman ruang sangat baik dengan rasio $D / H<1,50$, dimana dengan tinggi ambang atas bukaan yang ada diharapkan cahaya dapat mengakses ruang dalam 
dengan optimal. Pada kamar tidur 2 dan 4 kedalaman ruang baik dengan rasio $\mathrm{D} / \mathrm{H}<2,50$, dimana dengan tinggi ambang atas bukaan yang ada diharapkan cahaya masih dapat cukup menjangkau bagian dalam ruang. Kedalaman ruang pada ruang penerima kurang baik karena rasio $\mathrm{D} / \mathrm{H}>2,50$, tetapi masih dapat terbantu karena ruang bersifat open plan sehingga terhubung dengan ruang pertemuan yang memiliki cukup banyak ( 8 buah) bukaan cahaya JP2. Kedalaman ruang koridor kerja ditinjau dari bukaan J2 kurang baik, tapi tidak menimbulkan masalah karena sudah dapat diantisipasi oleh 4 bukaan cahaya J4.

Tabel 6. Kedalaman Ruang Gedung Negara

\begin{tabular}{|c|c|c|c|c|c|}
\hline Fungsi ruang & Tipe bukaan & Kedalaman ruang (D) & $\begin{array}{l}\text { Tinggi ambang } \\
\text { atas bukaan }(\mathrm{H})\end{array}$ & Rasio D/H & Kondisi desain \\
\hline \multirow[t]{2}{*}{ Kamar tidur 1} & $\mathrm{~J} 1$ & $5,27 \mathrm{~m}$ & $4,00 \mathrm{~m}$ & $5,72 / 4,00=1,43$ & $<1,50$ sangat baik \\
\hline & $\mathrm{J} 3$ & $6,50 \mathrm{~m}$ & $3,24 \mathrm{~m}$ & $6,50 / 3,24=2,01$ & $<2,50$ baik \\
\hline Kamar tidur 2 & $\mathrm{~J} 3$ & $6,50 \mathrm{~m}$ & $3,24 \mathrm{~m}$ & $6,50 / 3,24=2,01$ & $<2,50$ baik \\
\hline \multirow[t]{2}{*}{ Koridor kerja } & $\mathrm{J} 2$ & $12,41 \mathrm{~m}$ & $3,50 \mathrm{~m}$ & $12,41 / 3,50=3,55$ & $\begin{array}{l}>2,50 \text { kurang } \\
\text { baik }\end{array}$ \\
\hline & $\mathrm{J} 4$ & $3,35 \mathrm{~m}$ & $3,52 \mathrm{~m}$ & $3,35 / 3,52=0,95$ & $<1,50$ sangat baik \\
\hline Dapur & $\begin{array}{l}\text { (tidak } \\
\text { dikaji) }\end{array}$ & - & - & - & - \\
\hline \multirow[t]{2}{*}{ Ruang penerima } & JI & $11,30 \mathrm{~m}$ & $4,00 \mathrm{~m}$ & $11,30 / 4,00=2,83$ & $\begin{array}{l}>2,50 \text { kurang } \\
\text { baik }\end{array}$ \\
\hline & JP1 & $11,30 \mathrm{~m}$ & $4,00 \mathrm{~m}$ & $11,30 / 4,00=2,83$ & $\begin{array}{l}>2,50 \text { kurang } \\
\text { baik }\end{array}$ \\
\hline Ruang pertemuan & JP2 & $0,5 \times 9,30 \mathrm{~m}=4,65 \mathrm{~m}$ & $3,72 \mathrm{~m}$ & $4,65 / 3,72=1,25$ & $<1,50$ sangat baik \\
\hline Ruang peralatan & $\mathrm{J} 1$ & $5,27 \mathrm{~m}$ & $4,00 \mathrm{~m}$ & $5,27 / 4,00=1,32$ & $<1,50$ sangat baik \\
\hline Kamar tidur 4 & $\mathrm{~J} 3$ & $6,50 \mathrm{~m}$ & $3,24 \mathrm{~m}$ & $6,50 / 3,24=2,01$ & $<2,50$ baik \\
\hline Gudang & $\begin{array}{l}\text { (tidak } \\
\text { dikaji) }\end{array}$ & - & - & - & - \\
\hline
\end{tabular}

Sumber: R.P.D. Wigna, dkk. (2020) [5], diolah

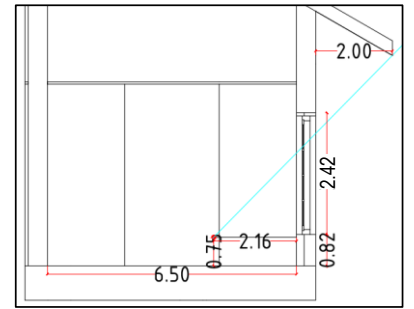

(a) Kamar tidur 1, bukaan J3

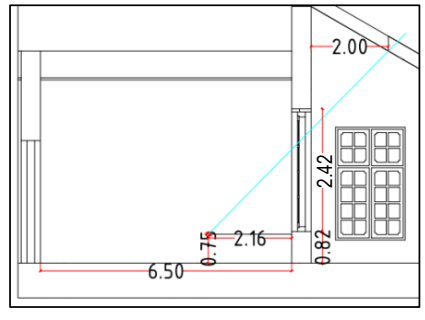

(b) Kamar tidur 2, bukaan J3

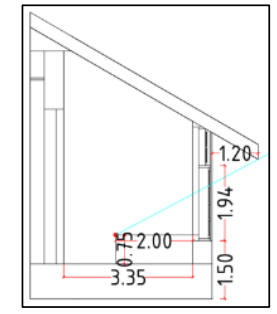

(c) Koridor kerja, bukaan J4

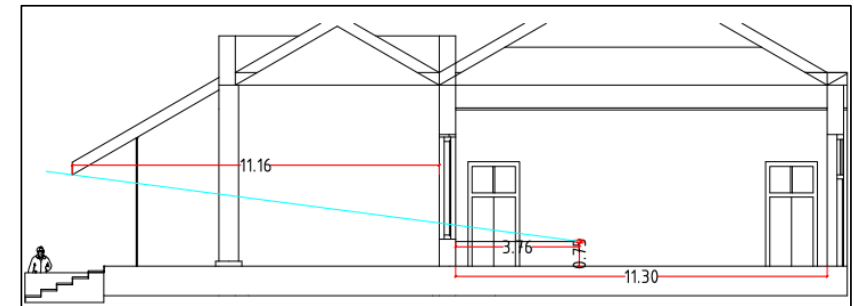

(d) Ruang penerima, bukaan J1

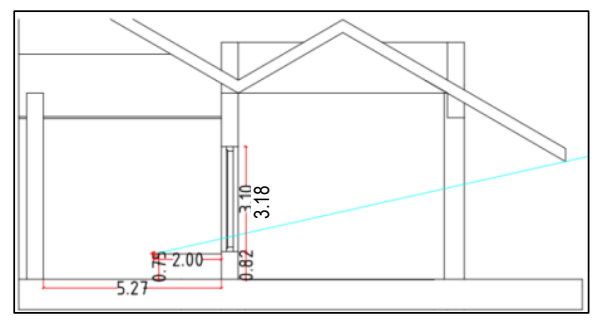

(f) Ruang peralatan, bukaan J1

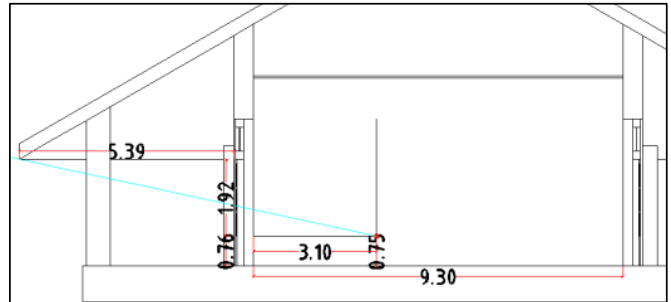

(e) Ruang pertemuan, bukaan JP2

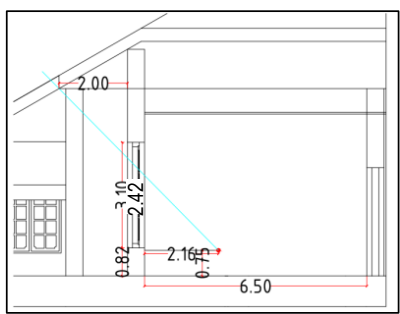

(g) Kamar tidur 4, bukaan J3

Gambar 5. Kedalaman Ruang Gedung Negara

Sumber: R.P.D. Wigna, dkk. (2020) [5], diolah 


\subsection{Spesifikasi Bukaan Cahaya}

Bukaan cahaya pada Gedung Negara menggunakan kaca bening/ clear glass tebal $5 \mathrm{~mm}$, maka kemampuan transmisi cahaya masih sangat baik mendekati $90 \%$. Bila menggunakan kaca setara Indofloat Clear Glass $5 \mathrm{~mm}$, maka kemampuan transmisi cahayanya sangat baik sebesar 89\%. Khusus tiap bukaan $\mathrm{J} 4$ pada fasad koridor kerja, bagian tengahnya menggunakan kaca es tebal $5 \mathrm{~mm}$, sedangkan bagian kiri kanannya masih menggunakan kaca bening tebal $5 \mathrm{~mm}$. Kemampuan transmisi kaca es dengan ketebalan ini di bawah $63 \%$ dengan efek cahaya difus tak menyilaukan, sehingga kualitas kaca ini masih dapat dikatakan baik walaupun cahaya yang ditransmisikan berkurang. Dengan spesifikasi kaca seperti ini pada seluruh bukaan pada Gedung Negara, maka sangat baik untuk memperoleh kuat penerangan yang mendukung kenyamanan visual bagi pengguna.

\subsection{Kuat Penerangan}

Kuat penerangan di lokasi diukur hanya pada 8 ruang yang diijinkan. Pada Tabel 7, standar RD untuk fungsi Gedung Negara sebagai rumah dinas, sedangkan standar FB bila difungsikan sebagai fasilitas budaya. Terkait standar RD, nilai faktor langit yang digunakan sebagai acuan untuk TUU \& TUS adalah 0,18.d \& 0,05.d untuk semua kamar tidur; 0,35.d \& 0,16.d untuk ruang penerima, koridor kerja, dan ruang peralatan; serta $0,20 . d \& 0,20 . d$ untuk dapur dan gudang. Terkait standar FB, nilai faktor langit yang diacu untuk TUU adalah 0,25.d dimana kerja visual mata pengguna dilakukan dengan kondisi melakukan kerja sedang, dan untuk TUS sebesar $40 \%$ dari TUU. Kuat penerangan yang terukur baik di lokasi pada ruang dalam menggunakan Luxmeter maupun hasil simulasi software menggunakan DIALux evo 8.2 (model dibuat dengan Revit 2020), harus memiliki nilai rata-rata yang tidak kurang dari nilai standar.

Tabel 7. Kuat Penerangan pada Ruang Gedung Negara

\begin{tabular}{|c|c|c|c|c|c|c|c|c|c|c|c|}
\hline \multirow{3}{*}{$\begin{array}{l}\text { Fungsi } \\
\text { ruang }\end{array}$} & \multirow{3}{*}{$\begin{array}{l}\text { Titik } \\
\text { ukur }\end{array}$} & \multirow{3}{*}{$\begin{array}{c}\text { Standar } \\
\text { RD } \\
\text { (lux) }\end{array}$} & \multirow{3}{*}{$\begin{array}{c}\text { Standar } \\
\text { FB } \\
(\operatorname{lux})\end{array}$} & \multicolumn{4}{|c|}{ Pengukuran di lokasi } & \multicolumn{3}{|c|}{ Simulasi software } & \multirow{3}{*}{$\begin{array}{l}\text { Ke- } \\
\text { sim- } \\
\text { pul- } \\
\text { an }\end{array}$} \\
\hline & & & & \multirow{2}{*}{$\begin{array}{c}\text { Rata-rata } \\
2 \text { sesi } \\
\text { (lux) }\end{array}$} & \multirow{2}{*}{$\begin{array}{c}\text { Rata-rata } \\
\text { semua titik } \\
\text { ukur (lux) }\end{array}$} & \multicolumn{2}{|c|}{ Kesimpulan } & \multirow{2}{*}{$\begin{array}{c}\text { Rata-rata } \\
3 \text { tanggal } \\
\text { (lux) }\end{array}$} & \multicolumn{2}{|c|}{ Kesimpulan } & \\
\hline & & & & & & $\begin{array}{c}\text { Standar } \\
\text { RD }\end{array}$ & $\begin{array}{c}\text { Standar } \\
\text { FB }\end{array}$ & & $\begin{array}{c}\text { Standar } \\
\text { RD }\end{array}$ & $\begin{array}{c}\text { Standar } \\
\text { FB }\end{array}$ & \\
\hline \multirow{2}{*}{$\begin{array}{l}\text { Kamar } \\
\text { tidur } 1\end{array}$} & TUU & 94,86 & 131,75 & 239,25 & \multirow{2}{*}{253,50} & $\mathrm{OK}$ & $\mathrm{OK}$ & \multirow{2}{*}{238,33} & $\mathrm{OK}$ & $\mathrm{OK}$ & $\mathbf{O K}$ \\
\hline & TUS & 26,35 & 52,70 & 260,63 & & $\mathrm{OK}$ & $\mathrm{OK}$ & & $\mathrm{OK}$ & $\mathrm{OK}$ & $\mathbf{O K}$ \\
\hline \multirow{2}{*}{$\begin{array}{l}\text { Kamar } \\
\text { tidur } 2\end{array}$} & TUU & 117,00 & 162,50 & 107,10 & \multirow{2}{*}{54,85} & $\mathrm{X}$ & $\mathrm{X}$ & \multirow{2}{*}{113,97} & $\mathrm{X}$ & $\mathrm{X}$ & $\mathbf{X}$ \\
\hline & TUS & 32,50 & 65,00 & 28,73 & & $\mathrm{X}$ & $X$ & & OK & $\mathrm{OK}$ & $\mathbf{X}$ \\
\hline \multirow{2}{*}{$\begin{array}{l}\text { Kamar } \\
\text { tidur } 3\end{array}$} & TUU & 149,40 & 207,50 & 10,25 & \multirow{2}{*}{8,90} & $\mathrm{X}$ & $\mathrm{X}$ & \multirow{2}{*}{7,84} & $\mathrm{X}$ & $\mathrm{X}$ & $\mathbf{X}$ \\
\hline & TUS & 41,50 & 83,00 & 8,23 & & $\mathrm{X}$ & $\mathrm{X}$ & & $\mathrm{X}$ & $\mathrm{X}$ & $\mathbf{X}$ \\
\hline \multirow{2}{*}{$\begin{array}{l}\text { Kamar } \\
\text { tidur } 4\end{array}$} & TUU & 117,00 & 162,50 & 18,50 & \multirow{2}{*}{37,33} & $\mathrm{X}$ & $\mathrm{X}$ & \multirow{2}{*}{44,70} & $\mathrm{X}$ & $\mathrm{X}$ & $\mathbf{X}$ \\
\hline & TUS & 32,50 & 65,00 & 46,75 & & $\mathrm{OK}$ & $\mathrm{X}$ & & $\mathrm{OK}$ & $\mathrm{X}$ & $\mathbf{X}$ \\
\hline \multirow{2}{*}{$\begin{array}{l}\text { Kamar } \\
\text { tidur } 5\end{array}$} & TUU & 149,40 & 207,50 & - & \multirow{2}{*}{ - } & - & - & \multirow{2}{*}{0,10} & $X$ & $X$ & $\mathbf{X}$ \\
\hline & TUS & 41,50 & 83,00 & - & & - & - & & $X$ & $X$ & $\mathbf{X}$ \\
\hline \multirow{2}{*}{$\begin{array}{l}\text { Kamar } \\
\text { tidur } 6\end{array}$} & TUU & 72,90 & 101,25 & - & \multirow{2}{*}{ - } & - & - & \multirow{2}{*}{0,02} & $\mathrm{X}$ & $X$ & $\mathbf{X}$ \\
\hline & TUS & 20,25 & 40,50 & - & & - & - & & $\mathrm{X}$ & $\mathrm{X}$ & $\mathbf{X}$ \\
\hline Ruang & TUU & 395,50 & 282,50 & 68,15 & & $\mathrm{X}$ & $\mathrm{X}$ & & $X$ & $X$ & $\mathbf{X}$ \\
\hline penerima & TUS & 180,80 & 113,00 & 41,53 & 54,84 & $X$ & $\mathrm{X}$ & 1,81 & $X$ & $X$ & $\mathbf{X}$ \\
\hline Ruang & TUU & 325,50 & 232,50 & 40,58 & & $X$ & $X$ & & $\mathrm{X}$ & $\mathrm{X}$ & $\mathbf{X}$ \\
\hline pertemuan & TUS & 148,80 & 93,00 & 31,05 & 36,11 & $X$ & $X$ & 11,82 & $\mathrm{X}$ & $X$ & $\mathbf{X}$ \\
\hline Koridor & TUU & 117,25 & 83,75 & 664,83 & & $\mathrm{OK}$ & $\mathrm{OK}$ & & $\mathrm{OK}$ & $\mathrm{OK}$ & $\mathrm{OK}$ \\
\hline kerja & TUS & 53,60 & 33,50 & 339,25 & 534,00 & $\mathrm{OK}$ & $\mathrm{OK}$ &, 00 & OK & $\mathrm{OK}$ & OK \\
\hline Ruang & TUU & 184,45 & 131,75 & 88,60 & & $\mathrm{X}$ & $\mathrm{X}$ & & $\mathrm{X}$ & $\mathrm{X}$ & $\mathbf{X}$ \\
\hline peralatan & TUS & 84,32 & 52,70 & 65,20 & 13,00 & $X$ & $\mathrm{OK}$ & $15,3 /$ & $X$ & $X$ & $\mathbf{X}$ \\
\hline Dapur & TUU & 81,00 & 101,25 & - & - & - & - & ח 21 & $X$ & $X$ & $\mathbf{X}$ \\
\hline & TUS & 81,00 & 40,50 & - & - & - & - & 0,21 & $\mathrm{X}$ & $\mathrm{X}$ & $\mathbf{X}$ \\
\hline Gudang & TUU & 100,00 & 125,00 & - & - & - & - & & $X$ & $X$ & $\mathbf{X}$ \\
\hline & TUS & 100,00 & 50,00 & - & - & - & - & 91,63 & $\mathrm{X}$ & $\mathrm{OK}$ & $\mathbf{X}$ \\
\hline
\end{tabular}

Sumber: R.P.D. Wigna, dkk. (2020) [5], diolah

Nilai D dan bukaan cahaya yang digunakan adalah kamar tidur $1 \mathrm{D}=5,27 \mathrm{~m}$ bukaan $\mathrm{J} 1$; kamar tidur 2 \& $4 \mathrm{D}=6,50 \mathrm{~m}$ bukaan $\mathrm{J} 3$; kamar tidur $3 \mathrm{D}=8,30 \mathrm{~m}$ bukaan $\mathrm{J} 1$; ruang penerima $\mathrm{D}=11,30 \mathrm{~m}$ bukaan 
JI \& JP1; ruang pertemuan $\mathrm{D}=9,30 \mathrm{~m}$ bukaan JP2; koridor kerja $\mathrm{D}=3,35 \mathrm{~m}$ bukaan $\mathrm{J} 4$; dan ruang peralatan $\mathrm{D}=5,27$ bukaan J1. Nilai D pada kamar tidur $5=8,30 \mathrm{~m}$; kamar tidur $6 \&$ dapur $=4,05 \mathrm{~m}$; sedangkan gudang $=5,00 \mathrm{~m}$. Pengukuran di lokasi dilakukan pada tanggal 7 Maret 2020 dalam 2 sesi pagi \& siang/ sore antara 08.00-16.00 dengan kondisi cuaca cerah berawan dan pencahayaan buatan dimatikan, lalu dihitung rata-rata TUU dan TUS $(1 \& 2)$ dari tiap sesi ini. Waktu simulasi software 1 sesi tengah hari pukul 12.00 tanggal 22 Juni 2020, 22 September 2020, dan 22 Desember 2020, lalu dari tiap tanggal ini dihitung rata-rata nilai minimal dan maksimal yang terjadi pada ruang model. Kuat penerangan yang tercantum pada Tabel 7 baik hasil pengukuran di lokasi maupun hasil simulasi software merupakan hasil rata-rata tersebut. Berdasarkan analisis, kuat penerangan yang diperoleh dalam ruang pada Gedung Negara baik sebagai rumah dinas maupun fasilitas budaya kurang baik karena yang memenuhi syarat standar hanya di kamar tidur 1 dan koridor kerja. Hal ini disebabkan saat pengukuran tirai-tirai pada bukaan cahaya dalam kondisi asli tidak dibuka seluruhnya dan terdapat interior/ furnitur dengan warna tidak muda yang bersifat kurang dapat memantulkan cahaya dengan baik (lihat Gambar 7).

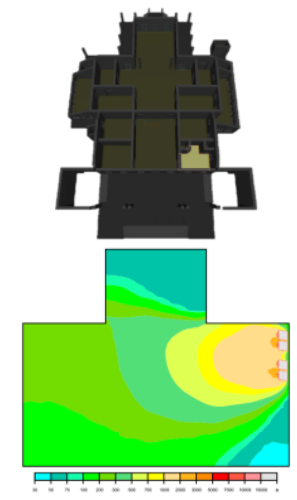

(a)

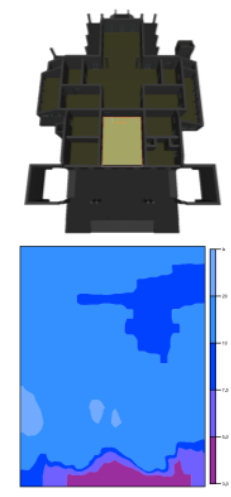

(b)

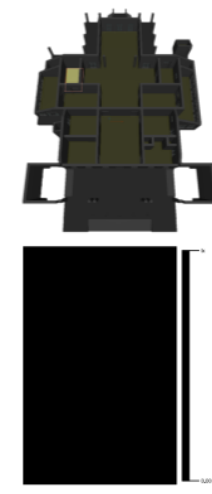

(c)

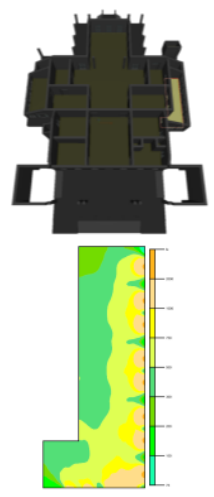

(d)
Keterangan:

(a) Kamar tidur 1 22 Juni 12.00 rata-rata $=508,00$ lux

(b) Ruang penerima 22 Juni 12.00 rata-rata 12,20 lux

(c) Kamar tidur 6 22 September 12.00 dengan rata-rata 0,01 lux

(d) Koridor kerja 22 Juni 12.00 rata-rata 620,00 lux

Gambar 6. Contoh Hasil Simulasi Software Sumber: R.P.D. Wigna, dkk. (2020) [5]

\subsection{Reflektansi Permukaan}

Warna interior ruang pada Gedung Negara didominasi oleh dinding finishing cat putih, plafon gipsum putih, lantai granit abu-abu/ hitam atau lantai ditutup karpet coklat/ coklat muda/ merah hati pucat/ hijau/ biru, pintu krem, serta furnitur kuning pucat hingga coklat tua [5]. Dinding warna putih sudah sangat baik karena kemampuan pantul cahayanya $80 \%-90 \%$, tetapi warna lantai dan furnitur yang tidak muda kurang baik karena kemampuan pantul cahayanya tidak lebih dari $25 \%$ sehingga menurunkan perolehan kuat penerangan dalam ruang yang diperlukan untuk mendukung tercapainya kenyamanan visual pengguna.

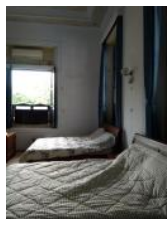

(a) Kamar tidur 1

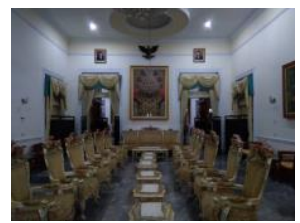

(e) Ruang penerima

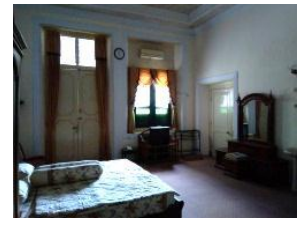

(b) Kamar tidur 2

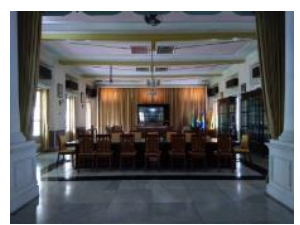

(f) Ruang pertemuan

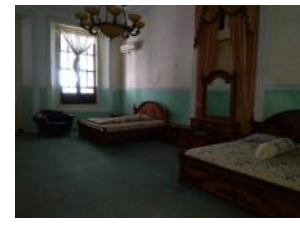

(c) Kamar tidur 3

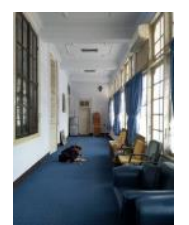

(g) Koridor kerja

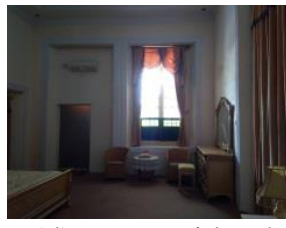

(d) Kamar tidur 4

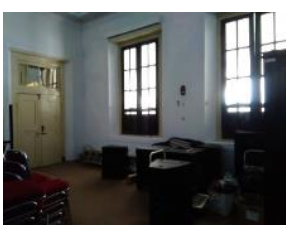

(h) Ruang peralatan

Gambar 7. Suasana Ruang Dalam di Gedung Negara Sumber: R.P.D. Wigna, dkk. (2020) [5] 


\section{SIMPULAN}

Simpulan terkait desain bangunan eks kolonial Gedung Negara ini sebagai berikut:

a. Orientasi bangunan dan bukaan cahaya serta spesifikasi bukaan cahaya sangat baik

b. Alokasi ruang; dimensi, bentuk, dan posisi bukaan cahaya; kedalaman ruang; serta reflektansi permukaan baik

c. Kuat penerangan terutama pada ruang-ruang di tengah bangunan kurang baik, kondisi ini dapat diperbaiki dengan mengganti karpet dan furnitur menjadi warna muda, membuka tirai lebih lebar, serta memasang cermin dalam ruang sebagai reflektor untuk meningkatkan efek pantulan cahaya.

\section{UCAPAN TERIMA KASIH}

Penelitian ini dilakukan berdasarkan kegiatan Pengabdian Kegiatan Masyarakat yang dilakukan Prodi Arsitektur Itenas-Bandung dengan melibatkan mahasiswa ARA 403 Seminar Arsitektur. Ucapan terima kasih diberikan pada pengelola Gedung Negara Cirebon atas ijin melakukan pengukuran lapangan, Prodi Arsitektur Sekolah Tinggi Teknik Cirebon sebagai mitra dalam melakukan survey PKM, serta LP2M Itenas yang telah memberi ijin dan mendanai kegiatan PKM ini.

\section{DAFTAR PUSTAKA}

[1] Handinoto, Arsitektur dan Kota-Kota di Jawa pada Masa Kolonial. Yogyakarta: Graha Ilmu, 2012.

[2] S. Wardiningsih, "Arsitektur Nusantara Mempengaruhi Bentuk Bangunan yang Berkembang di Indonesia," dalam SCALE, Volume 2, No. 2, 2015, hal. 274-283

[3] N. Syarief, dkk., "Eksplorasi Bangunan Cagar Budaya eks Kolonial di Kota Cirebon," Program Studi Arsitektur Itenas-Bandung, Bandung, Laporan Pelaksanaan Program Pengabdian Kepada Masyarakat, 2020

[4] Undang-undang No. 11 Tahun 2010 tentang Bangunan Cagar Budaya

[5] R.P.D. Wigna, dkk., "Penerapan Potensi Pencahayaan Alami pada Bangunan Eks Kolonial," Program Studi Arsitektur Itenas Bandung, Bandung, Laporan ARA 403 - Seminar Arsitektur, 2020.

[6] Tata Cara Perancangan Sistem Pencahayaan Alami pada Bangunan Gedung, SNI 03-2396-2001, Badan Standardisasi Nasional, Jakarta, 2001.

[7] N.L. Latifah, Fisika Bangunan 1 - Penghawaan Alami \& Penerangan Alami; Pengendalian Termal (Solar Chart \& SPSM). Jakarta: Griya Kreasi, 2015.

[8] M.C.L. William, Sunlighting as Formgiver for Architecture. New York: Van Nostrand Reinhold Company, 1986.

[9] P. Manurung, Cahaya dan Arsitektur. Yogyakarta: Teknosain, 2017.

[10] J. Livingston, Designing with Light: The Art, Science, and Practise of Architectural Lighting Design. New Jersey: John Wiley \& Sons, Inc., 2014.

[11] D. Philips, Daylighting: Natural Light in Architecture. Burlington: Architectural Press, 2004.

[12] P. Manurung, Pencahayaan Alami dalam Arsitektur. Yogyakarta: CV. Andi Offset, 2012.

[13] R.D. Chaerani, dkk., "Optimalisasi Bukaan Jendela untuk Pencahayaan Alami dan Konsumsi Energi Bangunan," dalam e-Proceeding of Engineering, Vol. 4, No. 3, Desember 2017. [Online]. Akses: https://core.ac.uk/download/pdf/299917617.pdf

[14] M.D. Pangestu, Pencahayaan Alami dalam Bangunan. Bandung: Unpar Press, 2019.

[15] Y.B. Mangunwijaya, Pengantar Fisika Bangunan. Jakarta: Djambatan, 2000.

[16] Katalog Asahimas Architectural Glass, hal. 59.

[17] G.Z. Brown, "Matahari, Angin, dan Cahaya - Strategi Perancangan Arsitektur," Bandung: Intermatra (dalam Bahasa Indonesia), 1990. 